\title{
PREDATION, NATURAL SELECTION AND ADAPTATION IN AN UNUSUAL THREESPINE STICKLEBACK
}

\author{
G. E. E. MOODIE* \\ Department of Zoology, University of Alberta, Edmonton, Alberta, Canada
}

Received 17.v.71

\section{INTRODUCTION}

THE study of biological variation in terms of the organism's adaptation to its environment is a most revealing approach to understanding diversity. This is exemplified in the classical studies of the ecological genetics of the snail, Cepea nemoralis and various lepidopterans reviewed by Ford (1964) and Sheppard (1969). Such studies of natural selection in the wild have greatly contributed to our knowledge of such phenomena as adaptation, selective agents and their modes of action, intensity of natural selection, and maintenance of polymorphism, to name only a few. Most of this work has dealt with invertebrates. In the Queen Charlotte Islands, Canada, several populations of a vertebrate, the threespine stickleback, Gasterosteus aculeatus L., have diverged markedly from the typical $G$. aculeatus in respect to their morphology, ecology, and sometimes behaviour, much of the variation appears to be correlated with the presence or absence of predators. In Mayer Lake (latitude $53^{\circ} 40^{\prime} \mathrm{N}$, longitude $132^{\circ} 02^{\prime} \mathrm{W}$ ) individuals of one of these divergent populations are termed "Black" sticklebacks and are characterised by their large size, relatively long pelvic spines, average of seven lateral plates per side, and frequent absence of red pigmentation on the throat of sexually mature males. Black sticklebacks are parapatric with the typical, unkeeled, partially-plated form termed leiurus by European workers. Leiurus individuals are smaller than Black sticklebacks, have relatively short pelvic spines, an average of five lateral plates per side, and sexually mature males usually have red pigmentation on the throat. Various aspects of the ecology, life-history, and morphology of the two populations are discussed by Moodie (in press). The following is a study of selection operating in the form of predation on the unusual characteristics of the Black stickleback.

Black sticklebacks, together with prickly sculpin, Cottus asper Richardson; cutthroat trout, Salmo clarki Richardson; dolly varden char, Salvelinus malma (Walbaum); and coho salmon, Oncorhynchus kisutch (Walbaum), are found in the lake proper. Leiurus occurs only in the inlet streams of the lake, where all other fish species are absent (Moodie, unpubl.).

\section{EVIDENCE FOR PREDATION OF STICKLEBACKS}

Predatory fish were caught in $2.5 \mathrm{~m} . \times 15 \mathrm{~m}$. monofilament gill-nets set parallel to shore, and on the offshore side of breeding areas of the Black stickleback. On some occasions large-mesh gill-nets were set in amongst the nesting sticklebacks. Nets were left in the water continuously and the caught

* Present address: Department of Biology, University of Winnipeg, Winnipeg 2, Manitoba, Canada. 
fish removed at least twice daily. As soon as the fish were taken from the net, up to one ml. of concentrated formalin was placed in the stomach via the pharynx. This served to halt digestion, and harden fish remains. Within one to two hours the stomachs were opened, and the predator's length and stomach contents recorded. Stomach contents were labelled and placed in 10 per cent. formalin, either in a vial or wrapped in cheesecloth.

The importance of Black sticklebacks in the diet of the cutthroat trout is shown in fig. 1. Sticklebacks of all sizes (fig. 2) were the major food item in all months but one in which samples were taken. Sticklebacks were of secondary importance only during relatively brief periods when certain aquatic insect species were very abundant, as in July 1967. The reduced availability of insects in the winter may be correlated with the apparent increase in predation on sticklebacks (and sculpins) at this time, however, data are limited.

Eggs of the Black sticklebacks were found in about 30 per cent. of the adult prickly sculpin stomachs examined (fig. 1). Small numbers of juvenile sticklebacks and even small adults were also eaten. Although young sculpins were commonly observed feeding on larval sticklebacks after the parent had been frightened from the nest, larvae were never found in sculpin stomachs. Stickleback larvae are known to be digested very rapidly by some species, however (D. W. Hagen, personal communication). Field and laboratory observations, although very limited, suggest that sculpins took eggs from guarded nests; however, eggs could also be obtained from nests that had lost, or been abandoned by the parent and would therefore have died in any event (van Iersel, 1953).

A third predator of the Black stickleback the leech, Haemopis marmorata (Say) fed on eggs in the nest, ingesting them whole. Leeches were ubiquitous in the littoral zone of the lake and the number of eggs they consumed probably depended mainly on the attentiveness with which the male stickleback guarded his nest. Leeches were usually detected quite quickly unless they completely entered the nest, in which case they might remain over $30 \mathrm{~min}$ utes. When a leech was discovered in the territory itwas immediately grasped by the nest owner and deposited outside the territorial boundary. Consumption of 10 leeches, allowed to feed on stickleback eggs until satiated, ranged from 57 to 152 , with a mean of 94 .

Stomachs of the non-resident salmonids, S. malma and $O$. kisutch, contained only invertebrates.

Since $S$. clarki is probably the major predator on the Black stickleback, as well as the most easily studied, the following discussion concerns interactions between these two populations. Certain conclusions, however, may also pertain to predation on Black sticklebacks by sculpins.

Determination of the circadian feeding pattern of cut-throat trout was based on the assumption that feeding fish were more active and therefore more likely to be gill-netted than non-feeding fish. Two $15 \mathrm{~m}$. gill-nets were placed in $1.2 \mathrm{~m}$. of water parallel to shore on the offshore side of stickleback breeding areas in August 1967. Fish were removed from the net every four hours over an 8-day period. An alternative approach utilised an event recorder activated when trout attacked stickleback models. The device recorded such attacks with an accuracy of less than \pm 30 minutes. The recorder was operated in several locations and depths of water from May to September 1969. 

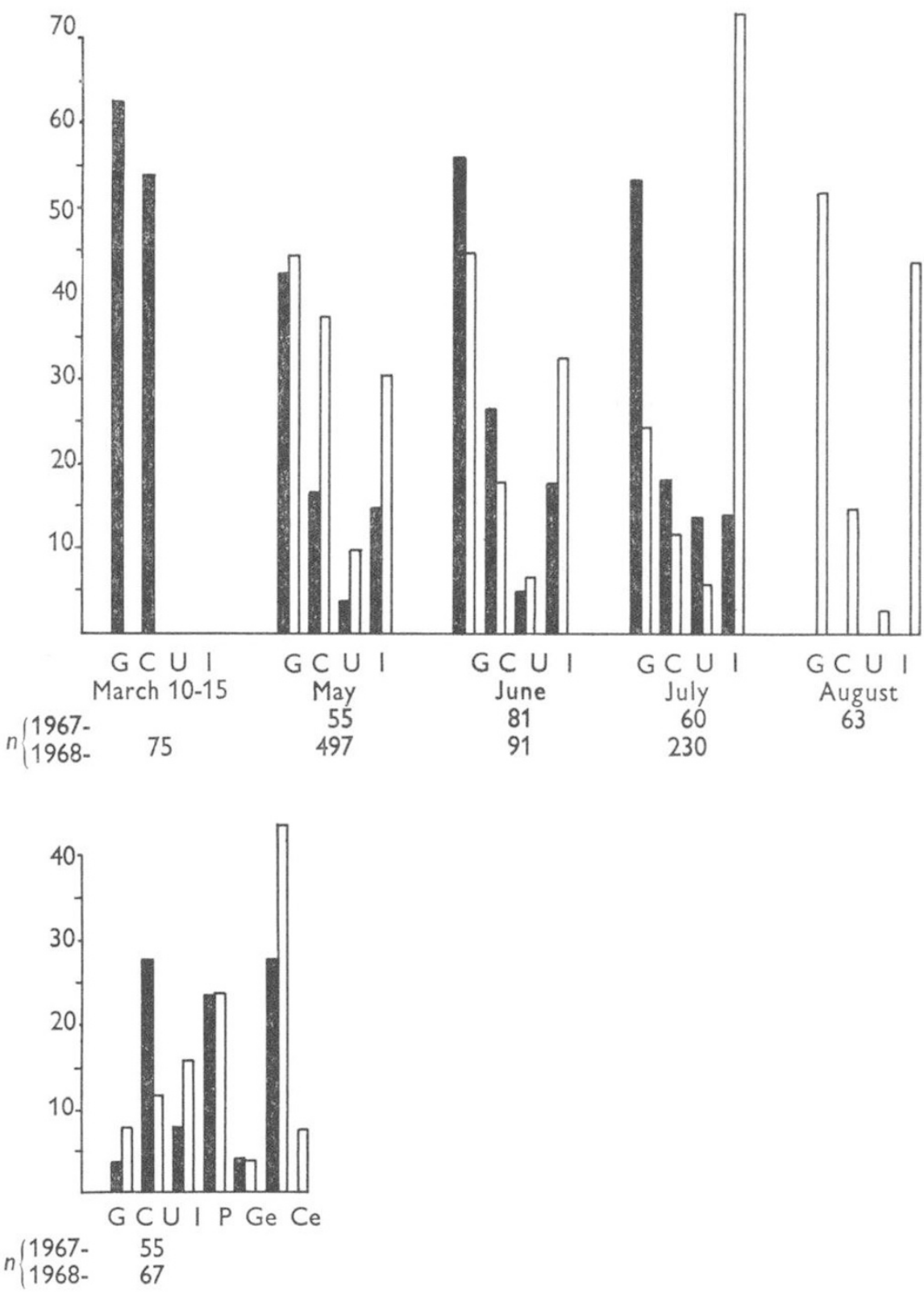

FIG. 1.-Diet of cutthroat trout and prickly sculpin. Vertical axis indicates percentage of guts containing the item. $\mathrm{G}=$ Gasterosteus, $\mathrm{C}=$ Cottus, $\mathrm{U}=$ unidentifiable fish, $\mathrm{I}=$ insects $\mathrm{P}=$ plant material, $\mathrm{Ge}=$ Gasterosteus eggs, $\mathrm{Ce}=$ Cottus eggs, open bars are for 1967 samples, closed bars are for 1968 samples.

The total number of cutthroat trout caught in the gill-nets in each 4-hour interval is shown in table 1. (Very small catches of sculpins showed a similar pattern.) The times at which trout attacked the model sticklebacks have been grouped into four intervals (table 1). Both sets of data clearly suggest that the cutthroat trout is a diurnal feeder. Differences in the times of 


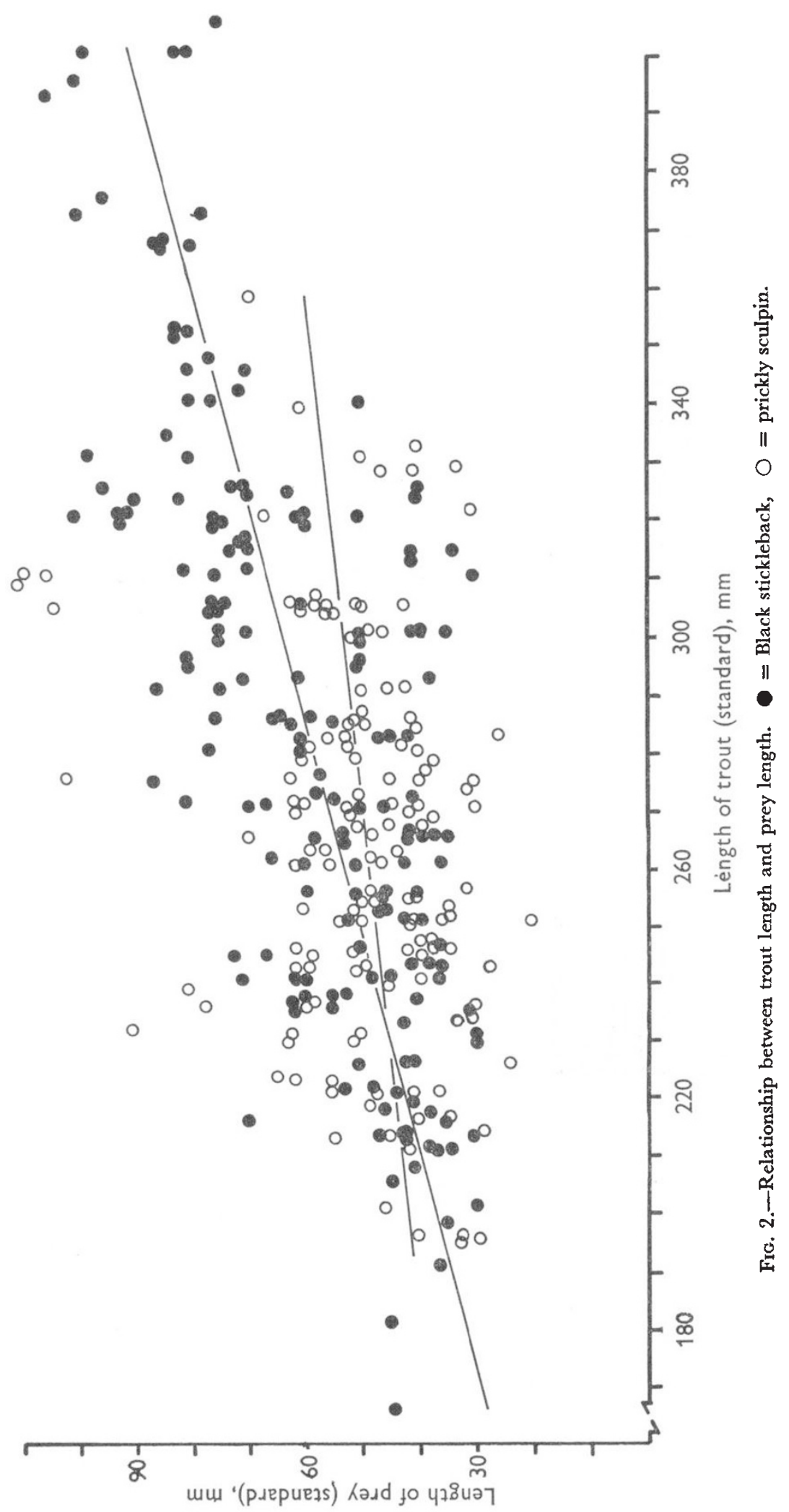


TABLE 1

Circadian activity and feeding rhythms of cutthroat trout

\begin{tabular}{|c|c|c|c|c|c|c|c|}
\hline \multirow{2}{*}{$\begin{array}{l}\text { Method } \\
\text { and } \\
\text { date }\end{array}$} & \multicolumn{6}{|c|}{ Time (hr.) } & \\
\hline & $1200-1600$ & $1600-2000$ & $2000-2400$ & $2400-0400$ & $0400-0800$ & $0800-1200$ & No. \\
\hline $\begin{array}{l}\text { Gill-net catches } \\
\text { (8-16 Aug. 1967) }\end{array}$ & 5 & 5 & 7 & 3 & 12 & 8 & 40 \\
\hline Model attacks & 21 & 11 & 10 & 1 & 13 & 16 & 72 \\
\hline
\end{tabular}

(7 May-

29 Aug. 1969)

maximum gill-net catches and model attacks (dawn and early afternoon, respectively) could be attributable to the differences in season and location of the two studies, or the difference in the parameters measured (activity and feeding). Of primary importance for this study is, that cutthroat trout are active in the daytime and are probably feeding then.

\section{Consequences of PREDATION ON THE EVOLUtion OF THE BLAGK STIGKLEBAGK}

The drab breeding colour of Black stickleback males, relatively long pelvic spines, lateral plate number mode, and large body-size, may have resulted from selection exerted by predators. Todetect such selection stomach contents of trout were examined and predator choice experiments conducted.

\section{(a) Breeding colour}

Only variation in throat colour was considered i.e. the adaptive significance of the loss of the red throat in over 80 per cent. of the population (Moodie, unpubl.). To determine whether males with red throats were more liable to predation than non-red males, the two colour types were presented in pairs to cutthroat trout at Seattle, Washington, in August 1968. The number of attacks made on each type was recorded. The trout (usually one, but sometimes four) were kept in a 550-litre aquarium. The aquarium was surrounded by a screen of black polyethylene plastic provided with a small peep-hole. A single 150-watt bulb centred over the tank supplied illumination when required. The six trout used were two- and three-year-old $S$. clarki from the Tokul Creek Hatchery, Washington. Sticklebacks used in the experiment were from Mayer Lake (Black form) and Wapato Lake, Washington (use of the latter was necessitated when the Mayer Lake fish became diseased). Like the Black stickleback, the Wapato fish are exposed to predation by trout (Salmo gairdneri Richardson) and only 14 per cent. of breeding males develop red throats (Semler, 1971).

The use of natural nuptial colours was not practicable because of the low frequency at which red males occur and the length of time required to bring fish into breeding condition and thus colour; all stickleback were therefore coloured artificially. Fish to be tested were matched in length to within two $\mathrm{mm}$., in general body colour, and in plate number. The throat region was blotted dry and melted lipstick was quickly applied with a fine camel hair brush. Each fish of a pair was so treated, the experimental with red lipstick (Hot Coral manufactured by Revlon Inc., colour 5R5/12 in the Munsell System, Anon. (1929)), the control fish with clear lipstick (Lip Gloss, manufactured by Bonne Bell, Inc.). 
The fish were simultaneously placed in the experimental aquarium in which the trout were kept and observation began. Each open-mouthed rush of the trout to within $2 \cdot 5 \cdot 5 \cdot 0 \mathrm{~cm}$. of the stickleback was recorded as an "attack". Each attack was terminated by turning off (or on, see below) the overhead light just as the trout was about to contact the prey. Termination was necessary in order to accumulate sufficient data since continued contact between trout and stickleback would eventually result in either avoidance because of the spines, or feeding satiation, depending on the size of the trout. Whenever the members of a stickleback pair showed dissimilar behaviour, both individuals were discarded. Often the attacks and escape responses resulted in some of the lipstick flaking off. When this occurred the pair was removed and the lipstick re-applied with the colours reversed on each fish in order also to reverse any hidden biases associated with either fish.

Three tests were made under the following conditions:

I Bright light and red coloration comparable to that of typical leiurus.

II Bright light and red coloration reduced to a single $1.2 \mathrm{~mm}$. dot on each operculum.

III Dim light $(<10 f c)$ and red coloration comparable to that of typical leiurus.

Trout showed a significant tendency to attack the experimental (redthroated) fish in all cases (table 2). Attacks on the fish with red throats were most frequent in bright light and when the red coloration was extensive (I). Reducing either the illumination or the amount of red coloration slightly reduced the number of attacks on the red-throated fish (II, III).

TABLE 2

Effect of throat colour of the stickleback on the likelihood of attack by trout

\begin{tabular}{lcccc} 
& \multicolumn{2}{c}{$\begin{array}{c}\text { Number of } \\
\text { attacks on }\end{array}$} & & \\
Test & Red & Dull & $\chi_{(1)}^{2}$ & P \\
right light & 42 & 13 & 15.29 & $<0.005$ \\
Dim light & 39 & 21 & 5.40 & $<0.025$ \\
right light & 40 & 18 & 8.34 & $<0.005$
\end{tabular}

Two male, two female $S$. clarki used in each test (I, II, III).

Black used in tests I and II, Wapato Lake fish used in test III.

Red coloration in I and II : from below anterior margin of eye back to rear of operculum (below eye) as well as down the midline of the throat to the isthmus.

Red coloration in III : a single dot $1.25 \mathrm{~mm}$. in diameter on the lower posterior quarter of each operculum.

\section{(b) Pelvic spine length}

Differential selection based on spine size was investigated by comparing the body length: spine length ratio of Black sticklebacks taken from cutthroat trout stomachs with a sample of equivalent standard length and sex taken from the lake by seine. Fish from the stomachs were measured only if recently swallowed and with the skin intact at head and tail.

Females taken from stomachs had a mean body length: pelvic spine length ratio of $5 \cdot 653$, significantly larger than that of females taken by seining; $5.419(t=2.084, \mathrm{P}<0.025$ (one tail), $d f=33$ ). Males taken from 
stomachs also had shorter pelvic spines than seined males but the difference was not significant. Possible bias in the measuring process was countered by having the fish measured by a colleague unaware of the purpose of the determinations. Bias due to digestion seems unlikely in that the null hypothesis should be favoured; the soft head and tail would be reduced before the bony spines, therefore leading to the conclusion that the spine length was relatively greater than was the case. That the spines do pose a difficulty for the trout is suggested by their significant preference (determined by stomach examination) to swallow sticklebacks head-first rather than tail-first $\left(\chi_{(1)}^{2}=7.4, \mathrm{P}<0.01\right)$. No such preference was shown when swallowing prickly sculpins which lack spines.

\section{(c) Lateral plate number}

The distinctly different distribution of lateral plate numbers in the Black stickleback and leiurus (Moodie, unpubl.), leads to questions about the adaptive value of these structures typical of the genus. Previous observations of various populations suggested a correlation between lateral plate number and predation (Hagen and Gilbertson, in press).

\section{TABLE 3}

Plate counts of Black sticklebacks taken by trout compared to those taken by seining

\begin{tabular}{lcccccc} 
Capture & \multicolumn{5}{c}{ Lateral plate number } & \\
$\quad \overbrace{\text { method }}$ & 5 & 6 & 7 & 8 & 9 & No. \\
By trout & 2 & 15 & 76 & 13 & 1 & 107 \\
By seining & 2 & 22 & 78 & 2 & - & 104 \\
\multicolumn{1}{c}{$\chi_{(1)}^{2}$ (between } & 8's and all others) & $=6.87$, & $\mathrm{P}<0.01$. &
\end{tabular}

Plate counts of Black sticklebacks taken from trout stomachs in 1967 and 1968 were compared with samples taken from the lake by seine. When digestion was apparent, plates were counted only if the skin was intact at both ends of the plate series and their contiguity indicated none had been lost. When a choice was possible, the count on the left side of fish taken from the stomachs was used to establish the frequency distribution. Seine-caught fish matched the prey-fish in year of capture, size, and sex (to the extent that digestion permitted the latter two to be determined).

Seine-caught fish were also used to establish the distribution of plate numbers among the different age classes and between the sexes.

A significant $(P<0 \cdot 01)$ excess of fish with eight lateral plates was found in the trout stomachs, indicating differential predation on this phenotype (table 3). Fish with six lateral plates were under-represented in the stomach sample, suggesting that they were less liable to predation than other phenotypes, however, the difference is not significant. Seven-plated fish were at similar frequencies in both stomach and seined samples.

Stabilising selection over three size classes approximating fry, yearling, and adult ages was suggested (table 4 ), but the reduction in variance was not significant $(0 \cdot 2>P>0 \cdot 1)$. Unfortunately plates are not fully formed and countable until the fish are about 20-25 mm. long (Lindsey, 1962; Hagen and McPhail, 1970) i.e., about two months old, by which time they have undergone considerable selection, some of which may have been for traits correlated with plate number. 
TABLE 4

Distribution of plate counts in three size classes corresponding approximately to the ages indicated

Lateral plate number

$\begin{array}{lcccccccccccc}\text { Age } & 5-4 & 5-5 & 5-6 & 6-6 & 6-7 & 7-7 & 7-8 & 8-8 & 7-5 & 7-9 & 8-6 & \text { No. } \\ \text { Fry } & - & 4 & 8 & 31 & 58 & 153 & 18 & 8 & 2 & - & 1 & 283 \\ \text { Yearling } & - & 3 & 5 & 45 & 68 & 175 & 10 & 3 & 2 & 1 & - & 312 \\ \text { Adult } & 2 & 1 & 2 & 31 & 49 & 187 & 19 & 3 & 1 & - & - & 295\end{array}$

$\chi_{(10)}^{2}(3 \times 6$ contingency table. Six columns obtained by pooling into two classes counts of 5-4, 5-5, 5-6 and counts of 8-8, 7-5, 7-9, 8-6) $=15 \cdot 75, \mathrm{P}<0 \cdot 2$.

Sexually mature females had significantly $(P<0.05)$ fewer lateral plates than did sexually mature males (table 5 ), such that there were relatively few

TABLE 5

Plate counts of sexually mature Black females compared to those of sexually mature males

\begin{tabular}{ccccccc} 
& \multicolumn{5}{c}{ Lateral plate number } \\
\cline { 2 - 6 } Sex & $5-6$ & $6-6$ & $6-7$ & $7-7$ & $7-8$ & No. \\
Males & 8 & 82 & 110 & 464 & 38 & 702 \\
Females & 6 & 32 & 47 & 135 & 5 & 225 \\
& & & & \\
& & &
\end{tabular}

females with counts of 7-7 and 7-8 and relatively more with counts of 6-7, 6-6, and 5-6. The entire plate distribution seems slightly skewed in the direction of that of leiurus (Moodie, in press).

\section{(d) Body size}

Large fish, because of size alone, should be more difficult for a given predator to swallow than small fish. When the prey bears projections such as spines the correlation between prey size and predator might be expected to increase. Data on prey size (sticklebacks and sculpins) were available from trout stomach samples. Only sexually mature female Black sticklebacks were considered for intra-population comparisons because estimates of mean length of juveniles could not be obtained. Males were excluded because of the difficulty in determining whether or not specimens from the stomachs were sexually mature.

The mean length of sexually mature females in the population was 89.9 $\mathrm{mm} .(n=105)$. The mean length of such females taken from trout stomachs was $87.0 \mathrm{~mm}$. ( $n=33)$. The difference was not significant, however. The difference in the slope of the regression lines of predator (trout) length on prey (Black stickleback and sculpin) length (fig. 2) suggests a more direct relationship between stickleback length and trout length, than between sculpin length and trout length. (The two slopes are significantly different, $t=3.41, d f=306, \mathrm{P}<0.001)$. The correlation coefficients provide similar evidence, $r=0.721$ for the sticklebacks, but $r=0.314$ only for the sculpins.

While the data do not demonstrate differential predation based on body length, they do offer support for the hypothesis that predation on large sticklebacks should be less intense than on smaller ones.

With a single exception, there were no obvious correlations between breeding colour of Black males, pelvic spine length, lateral plate number and 
body size. Multiple regression analysis showed no significant $(P>0 \cdot 1)$ association between breeding colour, lateral plate number, and body size. A separate, simple analysis of variance indicated there was no correlation $(P>0.1)$ between lateral plate number and pelvic spine length. However, when actual pelvic spine length was plotted against body length it was apparent that very large individuals tended to have relatively shorter spines than did fish of a more normal length. The data did not allow a test for correlations between breeding colour of males and pelvic spine length.

\section{Discussion}

Contrary to the suggestion of Assem (1967) that G. aculeatus " may have only few aquatic predators", this study as well as several others (Frost, 1954; Greenbank and Nelson, 1959; Carl, Clemens and Lindsey, 1967; Foerster, 1968; Legget and Power, 1969) in geographically distant localities demonstrate that sticklebacks are commonly preyed upon by various species. In Mayer Lake cutthroat trout feed on Black sticklebacks of all ages, and prickly sculpins occasionally capture juveniles. Eggs of Black sticklebacks are eaten by both prickly sculpins and leeches. Various ways in which the Black stickleback has adapted to the selective pressure of predation are considered here.

Throat colour appears to be under genetic control in several populations (McPhail, 1969; D. W. Hagen, personal communication) and such control is therefore assumed in the Mayer Lake sticklebacks. Work toward an understanding of the apparent polymorphism consisted, in this study, simply of a consideration of potential selective forces acting on the two colour morphs.

The disproportionate number of trout attacks on sticklebacks having red throats in the choice experiments offers an explanation for the loss of the red throat in the bulk of the population. Sculpins as well may select against fish with red throats, when feeding on eggs, since stickleback nests are often most easily located (at least by humans) by observing the parental behaviour of the male.

Preliminary efforts to determine the function of the red throat, present in 14-18 per cent. of the population, were unsuccessful. Pelkwijk and Tinbergen (1937) found in a monomorphic red population females would show courtship behaviour to a red-throated model but not to a model without a red throat. In the present study sexual selection based on throat colour was not evidenced in choice tests in which females could display the " headup " posture to a male of either type. Clutch sizes of red and non-red males nesting in the lake were not significantly different from each other, which further suggests the absence of sexual selection acting on throat colour. However, Semler (1971), using fish from Wapato Lake, where, as in Mayer, only 14 per cent. of males are red-throated, found in his more elegant choice tests, that females would deposit their eggs in the nests of red males more often than in the nests of non-red males.

Pelkwijk and Tinbergen (1937) suggested the red throat serves as a threat signal since they observed males to be less willing to enter a recently vacated territory occupied by a red-throated model than by a non-red model. Semler (1971) found 52 per cent. of breeding males in Wapato Lake were preying on stickleback eggs which would surely place a premium on adaptations reducing territorial intrusions. In Mayer Lake 33 per cent. of adult 
males $(n=104)$ had stickleback eggs in their stomachs. The frequent intensification of the red throat colour toward the end of the breeding cycle, after courtship is completed, and the red pigmentation of the buccal cavity of most Black males (Moodie, unpubl.), visible when fish gape as they often do during territorial disputes, suggests a threat rather than a sexual function. The questions posed by the presence of red males in otherwise cryptically coloured populations clearly invites further experimentation.

Hoogland, Morris and Tinbergen (1956) have provided a good description of the effectiveness of the spines of $G$. aculeatus on predators. The longspined Black stickleback in Mayer Lake and the short-spined leiurus of the inlet streams of the lake typify a general pattern described by Hagen and Gilbertson (in press) who surveyed many populations and found a direct correlation between pelvic spine length and the level of predation. The preponderance of short-spined Black sticklebacks in trout stomachs, together with Hagen's (1967) observation of a genetic control of spine length in leiurus and trachurus (the marine form of $G$. aculeatus) strongly suggests natural selection is acting on this character in the Black stickleback.

Long-spined fish could be favoured when they display the erect spines, especially the pelvic spines which bear a brightly coloured membrane. These displays occur when a predator is detected at close range. Selection is also probable during predator-prey contact. Predators vary in the manner in which they swallow a stickleback. Hoogland et al. (1956) note that the prey almost never escapes from the mouth of the pike (Esox lucius L.), but commonly escapes from the perch (Perca fluviatilis L.). I have observed similar behaviour in the squawfish (Ptychocheilus oregonense (Richardson)) and the cutthroat trout $(S$. clarki) respectively.

Cutthroat trout repeatedly manipulate the stickleback with their jaws seemingly in order to fold or break down the erect spines. During this process the stickleback often escapes. In a series of 100 presentations of sticklebacks to an experienced cutthroat trout I observed 39 escapes from the mouth. Like many distasteful species (Cott, 1957), sticklebacks are very " durable" and are often unscathed after such an escape. Hoogland et al. (1956) made similar observations.

The number of lateral plates of sticklebacks have long been used for taxonomic purposes. The risks of such usage are becoming apparent, however, for plate number is subject to strong selection (Hagen and McPhail, 1970; Hagen and Gilbertson, in press; present study). The heritability of plate number is well established (Lindsey, 1962; Hagen, 1967, and personal communication). The distribution of plate counts of Black sticklebacks in Mayer Lake and leiurus in the inlet streams of the lake reflects a widespread pattern, apparent in other populations in the Queen Charlotte Islands (unpublished, Moodie and Reimchen) and described in detail by Hagen and Gilbertson (in press) from a study of 55 populations in Washington, British Columbia, and Alaska. Populations subject to predation nearly always have a plate number mode of seven, whereas in populations not exposed to predators, modes at seven are unknown. Independent laboratory experiments by D. W. Hagen and J. D. McPhail (personal communication) show that predators capture fish with seven plates relatively less often than those with counts other than seven. In the present study fish with seven plates were at similar frequencies in both trout stomach samples and in those of the population at large. Differential predation is demonstrated, however, 
by the significant over-representation of fish with eight plates in the stomachs of trout. D. W. Hagen and L. G. Gilbertson (personal communication) have obtained similar evidence from examination of sticklebacks found in stomachs of S. gairdneri from Wapato Lake, and pike, Esox lucius L. from Aleknagik Lake, Alaska.

The basis for the differential predation is the subject of current tests. Preliminary observations suggest behavioural differences correlated with plate number influence survival. A small proportion of the Black sticklebacks have broken spines which probably resulted from attacks by trout. The frequency distribution of lateral plates in these fish $(n=82)$ is not different from that of the general population. This seems to indicate that plate number is irrelevant in determining survival once the predator has contacted the prey. Differential survival then may result from events prior to contact between predator and prey and thus be a result of behavioural differences. The best evidence at present that the plates themselves play no part in survival, is provided by McPhail's (1969) study of a population with a mode at seven (personal communication), which is exposed to predation only during the larval stages, prior to plate formation.

Female Black sticklebacks have significantly fewer lateral plates than males; their plate number distribution thus has a weaker mode at seven than that of males. The lack of territorial and parental behaviour, as well as the large size of females may expose them to less predation than males and result in a distribution of plate numbers skewed towards that of populations exposed to lower levels of predation. Other factors may be involved as well, however, for in certain populations (Gilbertson, Reimchen, personal communication) this sexual dimorphism appears among juveniles and where predators are absent.

Certain differences in the microhabitat of the nest site were correlated with the plate number of the male. One of these variables, distance from the nest to cover, seems to be correlated with survival of the fry (Moodie, in press). Since these correlations were significant in only some samples, there is great need for further studies, preferably experimental.

The large size of the Black stickleback may provide various means of defence against predators. Swimming speed in fish is a function of body length; Bainbridge (1958) estimated speed increases in proportion to the 0.65 power of body length in Leuciscus leuciscus and Carassius auratus. Although it is unlikely that a stickleback could outpace a predator in sustained swimming; quick bursts of speed may be crucial in enabling fish to reach shelter or where shelter is absent to avoid capture by very rapidly " leaping" through the water and then remaining motionless (a common escape response). In the event of capture the larger fish are more likely to escape because they probably require greater manipulation in the mouth than smaller fish. Visual acuity increases with size in Aequidens portalegrensis, a cichlid (Baerends, Bennema and Vogelzang, 1960), and this may be a general relationship since it is correlated with increased retinal area. In the Black stickleback one would expect enhanced visual acuity to be the most advantageous in detecting predators.

Predation on the Black stickleback in Mayer Lake has apparently led to the evolution of defensive adaptations unusual for both their variety and extreme development. Similar adaptations occur elsewhere however (McPhail, 1969; Semler, 1971; Hagen and Gilbertson, in press). It is 
likely that predation has been a major selective force in the evolution of many fresh-water populations of $G$. aculeatus in the American northwest.

\section{Summary}

1. In Mayer Lake Gasterosteus aculeatus exists as two forms or " races". The Black form is subject to predation by three species. The leiurus form, restricted to the inlet streams and stream margins, has no known predators.

2. Predator choice tests suggested that Black males which develop red throats are more liable to predation than males without red throats.

3. Black females taken from trout stomachs had significantly shorter spines than females netted in the lake.

4. Significantly more fish with eight lateral plates were eaten by trout than was expected on the basis of their frequency in the population.

5. The large size of Black sticklebacks may provide various defences against predators.

Acknowledgments.--I am most grateful to Professor J. R. Nursall for supervising and generously supporting this research. I also thank Professor G. E. Ball and Dr J. S. Nelson for their help. Professor C. C. Lindsey financed an early trip to the study area. Drs D. W. Hagen and J. D. McPhail and Mr T. E. Reimchen provided invaluable encouragement and practical assistance. Professor P. M. Sheppard kindly read the manuscript. To all these people I express my deep gratitude.

\section{REFERENGES}

ANon. 1929. The Munsell book of color. Baltimore, Munsell Color Company.

ASSEM, J. VAN DEN. 1967. Territory in the three-spined stickleback Gasterosteus aculeatus L. An experimental study in intra-specific competition. Behaviour Suppl., 16.

BAERENDS, G. P., BENNEMA, B. E., AND vogelZANG, A. A. 1960. Über die änderung der sehschärfe mit dem wachstum bei Aequidens portalegrensis (Hensel) (Pisces, Cichlidae). Zool. Fb. Abt. Syst., Okol. Geogr. Tierre, 88, 67-78.

BAINBRIDGE, R. 1958. The speed of swimming fish as related to size and to frequency and amplitude of the tail beat. F. Exp. Biol., 35, 109-133.

CARL, G. C., GLEMENS, w. A., AND LINDSEY, C. c. 1967. The fresh-water fishes of British Columbia, 4 ed. Victoria. British Columbia Provincial Museum Handbook No. 5.

сотт, н. в. 1957. Adaptive coloration in animals. London, Methuen.

FOERSTER, R. E. 1968. The sockeye salmon, Onchorhynchus nerka. Fisheries Research Board of Canada, Bull. 162.

FORD, E. B. 1964. Ecological genetics. London, Methuen.

FROST, w. E. 1954. The food of the pike, Esox lucius L. in Lake Windermere. F. Anim. Ecol., 23, 339-360.

GREENBANK, J., AND NELSON, P. R. 1959. Life-history of the three-spine stickleback Gasterosteus aculeatus Linnaeus in Karluk Lake and Bare Lake, Kodiak Island, Alaska. U.S. Fish. and Wildlife Serv. Fish. Bull. No. 153.

HAGEN, D. w. 1967. Isolating mechanisms in three-spine sticklebacks (Gasterosteus). F. Fish. Res. Bd. Canada, 24, 1637-1692.

HAGEN, D. W., AND MCPHAIL, J. D. 1970. The species problem within Gasterosteus aculeatus on the Pacific Coast of North America. 7. Fish. Res. Bd. Canada, 27, 147-155.

HAGEN, D. W., AND GILBERTSON, L. G. In press. Geographic variation and environmental selection in Gasterosteus aculeatus L. in the Pacific Northwest, America. Evolution

HOOGLAND, R., MORRIS, D., AND TTNBERGEN, N. 1956. The spine of sticklebacks (Gasterosteus and Pygosteus) as a means of defence against predators (Perca and Esox). Behaviour, 10, 200-230.

IERSEL, J. VAN. 1953. An analysis of the parental behaviour of the three-spine stickleback (Gasterosteus aculeatus L.). Behaviour Suppl. 3.

LEGGET, W. C., AND POWER, G. 1969. Differences between two populations of landlocked Atlantic salmon (Salmo salar) in Newfoundland. F. Fish. Res. Bd. Canada, 26, 1585-1596. 
LINDSEY, C. C. 1962. Experimental study of meristic variation in a population of threespine sticklebacks, Gasterosteus aculeatus. Can. F. Zool., 40, 271-311.

MCPHAIL, J. D. 1969. Predation and evolution in a stickleback (Gasterosteus). F. Fish. Res. Bd. Canada, 26, 3183-3208.

PELKWIJK, J. J. TER, AND TINBERGEN, N. 1937. Eine reizbiologische analyse eineger verhaltensweisen von Gasterosteus aculeatus L. Z. Tierpsychol., 1, 193-204.

SEMLER, D. E. 1971. Some aspects of adaptation in a polymorphism for breeding colours in the threespine stickleback (Gasterosteus aculeatus L.). F. Zool. Lond., 165, 291-302.

SHEPPARD, P. M. 1969. Evolutionary genetics of animal populations: the study of natural populations. Proc. XII Intern. Congr. Genetics, 3, 261-279. 